\title{
Antioxidant and Lipoxygenase Inhibitory Activity of the Kino of Eucalyptus citriodora
}

\author{
W. J. HUNG ${ }^{1}$, Z. T. CHEN AND S. W. LEE* \\ Department of Medicinal Chemistry, ${ }^{1}$ Department of Cosmetic Science and Institute of Cosmetic Science, Chia Nan University \\ of Pharmacy and Science, Tainan 71710, Taiwan
}

Hung et al.: Antioxidant and Lipoxygenase Inhibitory Activity of Eucalyptus citriodora

In the present study, antioxidant activity, total phenolic and flavonoid content, and 15-lipoxygenase inhibitory activity of ethanol extract and its ethyl acetate, n-butanol and aqueous fractions of Eucalyptus citriodora kino were evaluated. The antioxidant activity was determined using 2,2-diphenyl-1-picrylhydrazyl and 2,2'-azinobis(3-ethylbenzothiazoline-6-sulfonic acid) methods. The $\mathrm{IC}_{50}$ values of the ethanol extract were 5.11 \pm 0.13 , $2.72 \pm 0.08$ and $25.86 \pm 1.81 \mu \mathrm{g} / \mathrm{ml}$ in the 2,2-diphenyl-1-picrylhydrazyl, 2,2'-azino-bis(3-ethylbenzothiazoline6-sulfonic acid) methods and the 15-lipoxugenase assay, respectively. Total phenolic and flavonoid content of the ethanol extract were $490.77 \pm 1.95 \mathrm{mg}$ catechin equivalents/g and $21.81 \pm 0.23 \mathrm{mg}$ quercetin equivalents/g, respectively. Solvent partition of the ethanol extract yielded ethyl acetate, $n$-butanol and aqueous fractions. Among the three fractions, the ethyl acetate fraction showed the highest total phenolic and flavonoid contents, which were $575.87 \pm 3.92 \mathrm{mg}$ catechin equivalents/g and $34.57 \pm 0.30 \mathrm{mg}$ quercetin equivalents $/ \mathrm{g}$, respectively. This fraction also showed the strongest free radical scavenging activity in the two methods used as well as inhibitory activity against 15 -lipoxygenase, with $\mathrm{IC}_{50}$ values of $4.67 \pm 0.09,2.57 \pm 0.06$ and $14.67 \pm 0.93 \mu \mathrm{g} / \mathrm{ml}$, respectively. These findings revealed that high antioxidant and lipoxygenase inhibitory activity of Eucalyptus citriodora kino might be due to high phenolic and flavonoid content. These results showed that Eucalyptus citriodora kino could be a potential source of natural antioxidants and lipoxygenase inhibitors which could be used to prevent free radical and lipoxygenase mediated diseases.

Key words: Eucalyptus citriodora, kino, antioxidant, phenolic content, flavonoid content, lipoxygenase

It is well known that free radicals are associated with many diseases, including cancer, autoimmune disorders, cataract formation, rheumatoid arthritis, cardiovascular and neurodegenerative diseases. Antioxidants can scavenge free radicals and prevent oxidative stressrelated disease ${ }^{[1]}$. Lipoxygenases are dioxygenases that can catalyse the formation of corresponding hydroperoxides from polyunsaturated fatty acids that are responsible for a variety of conditions such as inflammation, atherosclerosis, neuronal disorders and tumor ${ }^{[2]}$. Studies have shown that polyphenolic compounds can inhibit lipoxygenase activity ${ }^{[3]}$. Plants produce a significant amount of antioxidant compounds, including polyphenols. Such compounds can prevent the oxidative stress-related diseases caused by free radicals ${ }^{[4]}$.

Many species of eucalyptus were used in folk medicine for the treatment of various medical conditions. For instance, hot water extracts of dried leaves of Eucalyptus citriodora are traditionally used as analgesic, antiinflammatory and antipyretic remedies for symptoms of respiratory infections such as cold, influenza and sinus congestion ${ }^{[5]}$. Many species of eucalyptus produced kino, a reddish-brown resinous material in response to injury or disease ${ }^{[6]}$. Eucalyptus kinos have shown to be antioxidant, liver protective, antiviral and antimicrobial and these were also used internally to treat diarrhoea, dysentery, wounds, ulcers, infections, cough, cold and influenza ${ }^{[7,8]}$. The main constituents of eucalyptus kino are mostly polyphenolic compounds, including tannins, flavonoids, anthocyanidins, lignans and other phenolic compounds ${ }^{[8,9]}$.

E. citriodora, a tree native to Australia, is widely grown in different parts of the world and is commonly cultivated in Taiwan. The kino of this plant has been

This is an open access article distributed under the terms of the Creative Commons Attribution-NonCommercial-ShareAlike 3.0 License, which allows others to remix, tweak, and build upon the work non-commercially, as long as the author is credited and the new creations are licensed under the identical terms

Accepted 12 July 2018

Revised 18 December 2017

Received 23 March 2017

Indian J Pharm Sci 2018;80(5):955-959 
discovered as a botanical origin for propolis ${ }^{[10,11]}$. Phytochemical studies on E. citriodora kino have described the isolation and characterization of triterpenoids, phenolics and flavonoids ${ }^{[12,13]}$. Cytotoxic effect on human hepatoma HepG2 cells ${ }^{[14]}$, and antiproliferative activity and apoptosis induction of E. citriodora kino in melanoma $\mathrm{B} 16 \mathrm{~F} 10$ cells have been investigated ${ }^{[15]}$. E. citriodora kino was reported to be rich in polyphenolic compounds, which might contribute to antioxidant and lipoxygenase inhibitory activity. To the best of our knowledge, the antioxidant and lipoxygenase inhibitory activity of E. citriodora kino have not been investigated. Therefore, the aim of this study was to evaluate the antioxidant and lipoxygenase inhibitory activity of $E$. citriodora kino.

2,2-Diphenyl-1-picrylhydrazyl

(DPPH),

2,2'-azinobis(3-ethylbenzothiaoline-6-sulfonic acid) (ABTS), Folin-Ciocalteu reagent, 6-hydroxy-2,5,7,8tetramethylchroman-2-carboxylic acid (Trolox), $(+)$-catechin, quercetin, potassium persulfate and other chemicals were purchased from Sigma-Aldrich (Steinheim, Germany). 15-Lipoxygenase (type I, from soybean) and linoleic acid were purchased from Sigma (St. Louis, MO). UV spectra were obtained on a Cary $50 \mathrm{UV} / \mathrm{Vis}$ spectrophotometer.

E. citriodora kino was collected in May 2009 in Yung Kang, Tainan, Taiwan, and was identified at the Department of Biology, National Cheng Kung University. A voucher specimen (CNUNP0605) was deposited in the Natural Product Laboratory of Department of Medicinal Chemistry, Chia Nan University of Pharmacy and Science.

The dried powder of E. citriodora kino (520 g) was extracted with 1.51 of $95 \%$ ethanol for $6 \mathrm{~d}$ at room temperature. After filtration, the residues were further extracted twice under the same condition. The filtrates were combined and evaporated to dryness under reduced pressure. The dried residue (455 g) was suspended in water and extracted with ethyl acetate (EtOAc) and $n$-butanol $(n-\mathrm{BuOH})$, and water successively. The EtOAc, $n-\mathrm{BuOH}$ and aqueous extracts were separately combined and evaporated to dryness under reduced pressure. Three dried fractions, EtOAc (263 g), n-BuOH (132 g) and aqueous (58 g) were obtained.

The total phenolic and flavonoid content of the ethanol extract and its three fractions was analysed. These were also tested in the DPPH and ABTS assays to determine free radical scavenging potential. The ability of the ethanol extract and its three fractions to inhibit 15-lipoxygenase activity was also evaluated.

Total phenolic content was measured using FolinCiocalteu's phenol (FCP) reagent according to the method of Singleton et al. ${ }^{[16]}$ with minor modification and calculated using $(+)$-catechin as standard. For preparation of a calibration curve, $50 \mu 1$ of $(+)$-catechin $(0-1000 \mu \mathrm{g} / \mathrm{ml})$ in ethanol was mixed with $900 \mu \mathrm{l}$ of $2 \% \mathrm{Na}_{2} \mathrm{CO}_{3}$ solution. The reaction mixture was vortexed thoroughly and incubated at room temperature for $2 \mathrm{~min}$ and then $50 \mu \mathrm{l}$ of $50 \%$ FCP reagent (previously diluted with distilled water) was added. After incubation at room temperature for $30 \mathrm{~min}$, the absorbance was measured at $760 \mathrm{~nm}$. The samples $(50 \mu \mathrm{l}, 1000 \mu \mathrm{g} / \mathrm{ml})$ were mixed with the same reagent as described above. After $30 \mathrm{~min}$ of incubation, the absorbance was measured at $760 \mathrm{~nm}$. All measurements were done in triplicate and the values were expressed as means $\pm \mathrm{SD}$. The total phenolic content of the sample was calculated on the basis of the standard curve of $(+)$-catechin and expressed as milligrams of $(+)$-catechin equivalent per gram of dry sample.

Total flavonoid content was measured according to the method of Yen et al..$^{[17]}$ and calculated using quercetin as standard. For preparation of a calibration curve, after $500 \mu \mathrm{l}$ of quercetin $(0-100.0 \mu \mathrm{g} / \mathrm{ml})$ was mixed with $500 \mu 1$ of $1 \%$ 2-aminoethyl-diphenylborate solution, the absorbance was measured at $404 \mathrm{~nm}$. The samples $(500 \mu \mathrm{l}, 1000 \mu \mathrm{g} / \mathrm{ml})$ were mixed with the same reagent and the absorbance of the mixture was measured at 404 $\mathrm{nm}$. All measurements were done in triplicate and the values were expressed as means $\pm \mathrm{SD}$. Total flavonoid content of samples was calculated on the basis of the standard curve of quercetin and expressed as milligrams of quercetin equivalent per gram of dry sample.

DPPH radical scavenging activity was measured according to the method of Mensor et al.$^{[18]}$ with minor modification. A solution of $1 \mathrm{mM}$ DPPH in ethanol was prepared. The DPPH solution was diluted with ethanol to an absorbance of 0.90 at $517 \mathrm{~nm}$, then $100 \mu \mathrm{l}$ of sample was mixed with $900 \mu \mathrm{l}$ of DPPH solution. The reaction mixture was vortexed thoroughly and allowed to stand in the dark at room temperature for $30 \mathrm{~min}$. The absorbance of the mixture was measured at $517 \mathrm{~nm}$. Trolox was used as reference compound. All measurements were done in triplicate and the values were expressed as means \pm SD. The capability of the sample to scavenge the DPPH radical was calculated using the following Eqn., DPPH radical scavenging 
activity $(\%)=\left[\left(\mathrm{A}_{\mathrm{c}}-\mathrm{A}_{\mathrm{s}}\right) / \mathrm{A}_{\mathrm{c}}\right] \times 100$, where $\mathrm{A}_{\mathrm{s}}$ and $\mathrm{A}_{\mathrm{c}}$ were absorbance at $517 \mathrm{~nm}$ of the reaction mixture with sample and control (containing DPPH solution without sample), respectively.

ABTS scavenging activity was measured according to the method of Re et al.$^{[19]}$ with a minor modification. The ABTS radical was produced through the reaction between $7 \mathrm{mM}$ ABTS and $2.45 \mathrm{mM}$ potassium persulfate in water. This solution was stored in the dark for $24 \mathrm{~h}$ before use. This ABTS solution was diluted with ethanol to an absorbance of 0.70 at $734 \mathrm{~nm}$ and equilibrated at $30^{\circ}$, then $100 \mu \mathrm{l}$ of sample or trolox solution in various concentration was mixed with $900 \mu \mathrm{l}$ of diluted ABTS solution. After reaction at $30^{\circ}$ for $6 \mathrm{~min}$, the absorbance at $734 \mathrm{~nm}$ was measured. Appropriate solvent blank was run in each assay. Trolox was used as reference. All measurements were done in triplicate and the values were expressed as means \pm SD. The capability of the sample to scavenge the ABTS was calculated using the following Eqn., ABTS radical scavenging activity $(\%)=\left[\left(\mathrm{A}_{\mathrm{c}}-\mathrm{A}_{\mathrm{s}}\right) / \mathrm{A}_{\mathrm{c}}\right] \times 100$, where $\mathrm{A}_{\mathrm{s}}$ and $\mathrm{A}_{\mathrm{c}}$ are absorbance at $734 \mathrm{~nm}$ of the reaction mixture with sample and control (containing ABTS solution without sample), respectively.

15-Lipoxygenase enzyme activity was measured according to the method of Lyckander and Malterud ${ }^{[20]}$ with a minor modification. Borate buffer $(200 \mu 1, \mathrm{pH}$ 9.0) was added to $50 \mu \mathrm{l}$ of different concentrations of samples along with positive control quercetin and enzyme ( $500 \mu 1,400$ units/ml in borate buffer). Samples and quercetin were added as DMSO solutions. After incubation of the test solution for $4 \mathrm{~min}, 250 \mu \mathrm{l}$ linoleic acid was added and the change in the absorbance was measured for $60 \mathrm{~s}$ at $234 \mathrm{~nm}$. The enzyme solution was kept in ice and controls were measured at intervals throughout the experimental periods to ensure that the enzyme activity was constant. All measurements were done in triplicate and the values were expressed as means \pm SD. Quercetin, a well-known inhibitor of 15-lipoxygenase was employed as a reference compound $^{[20]}$. The capability of the sample to inhibit the 15-lipoxygenase was calculated using the following Eqn., 15-lipoxygenase inhibitory activity (\%) = $\left[\left(\mathrm{A}_{\mathrm{c}}-\mathrm{A}_{\mathrm{s}}\right) / \mathrm{A}_{\mathrm{c}}\right] \times 100$, where $\mathrm{A}_{\mathrm{s}}$ and $\mathrm{A}_{\mathrm{c}}$ are absorbance at $234 \mathrm{~nm}$ of the reaction mixture with sample and control (containing enzyme solution without sample), respectively.

All data were recorded as means \pm standard deviation (SD) and were obtained from experiments repeated at least three times. Analysis of variance was performed by ANOVA procedures. Significant differences between means were tested by Duncan's multiple range test at a level of $\mathrm{p}<0.05$.

Total phenolic and flavonoid content of ethanol extract and its three fractions of E. citriodora kino were shown in Table 1. The EtOAc fraction exhibited the highest total phenolic and flavonoid content, which was $575.87 \pm 3.92 \mathrm{mg}$ catechin equivalents $/ \mathrm{g}$ and $34.57 \pm 0.30 \mathrm{mg}$ quercetin equivalents/g, respectively.

DPPH and ABTS radical scavenging activities of ethanol extract and its three fractions of E. citriodora kino were shown in a dose-dependent manner and expressed as $\mathrm{IC}_{50}$ values. The ethanol extract, EtOAc, $n-\mathrm{BuOH}$ and aqueous fractions exhibited scavenging activity against $\mathrm{DPPH}$ with $\mathrm{IC}_{50}$ values of $511 \pm 0.13,4.67 \pm 0.09,5.48 \pm 0.1$ and $11.75 \pm 0.16 \mu \mathrm{g} / \mathrm{ml}$, respectively. Among them, the EtOAc fraction showed the highest DPPH scavenging activity than reference compound trolox $\left(\mathrm{IC}_{50} 4.92 \pm 0.11 \mu \mathrm{g} / \mathrm{ml}\right.$; fig. 1). The ethanol extract, EtOAc, $n-\mathrm{BuOH}$ and aqueous fractions exhibited scavenging activity against ABTS with $\mathrm{IC}_{50}$ values of $2.72 \pm 0.08,2.57 \pm 0.06$, $2.82 \pm 0.11$, and $6.73 \pm 0.12 \mu \mathrm{g} / \mathrm{ml}$, respectively. Among them, the EtOAc fraction showed the highest ABTS scavenging activity (fig. 2). Ethanol extract, EtOAc and $n$-BuOH fractions showed higher ABTS scavenging activity than reference compound trolox $\left(\mathrm{IC}_{50} 3.07 \pm 0.09 \mu \mathrm{g} / \mathrm{ml}\right)$.

15-Lipoxygenase assays of ethanol extract and its three fractions of $E$. citriodora kino were shown in a dosedependent manner and expressed as $\mathrm{IC}_{50}$ values. The ethanol extract, EtOAc, $n$-BuOH and aqueous fractions exhibited inhibitory activity against 15-lipoxygenase with $\mathrm{IC}_{50}$ values of $25.86 \pm 1.81,14.67 \pm 0.93,47.45 \pm 2.25$ and $103.56 \pm 4.19 \mu \mathrm{g} / \mathrm{ml}$, respectively. Among them, the EtOAc fraction showed the highest 15-lipoxygenase inhibitory activity (fig. 3).

TABLE 1: TOTAL PHENOLIC AND FLAVONOID CONTENT OF ETHANOL EXTRACT AND ITS THREE FRACTIONS OF EUCALYPTUS CITRIODORA KINO

\begin{tabular}{lcc}
\hline Fractions & $\begin{array}{c}\text { Total phenolic } \\
\text { content }(\mathrm{mg} \text { CE/g })\end{array}$ & $\begin{array}{c}\text { Total flavonoid } \\
\text { content }(\mathrm{mg} \mathrm{QE} / \mathrm{g})\end{array}$ \\
\hline Ethanol extract & $490.77 \pm 1.95$ & $21.81 \pm 0.23$ \\
Ethyl acetate & $575.87 \pm 3.92$ & $34.57 \pm 0.30$ \\
$n$-Butanol & $379.92 \pm 3.20$ & $2.37 \pm 0.04$ \\
Aqueous & $205.66 \pm 1.29$ & $0.60 \pm 0.04$ \\
\hline
\end{tabular}

Values are means \pm SD of three experiments. CE: catechin equivalents, $\mathrm{QE}$ : quercetin equivalents 


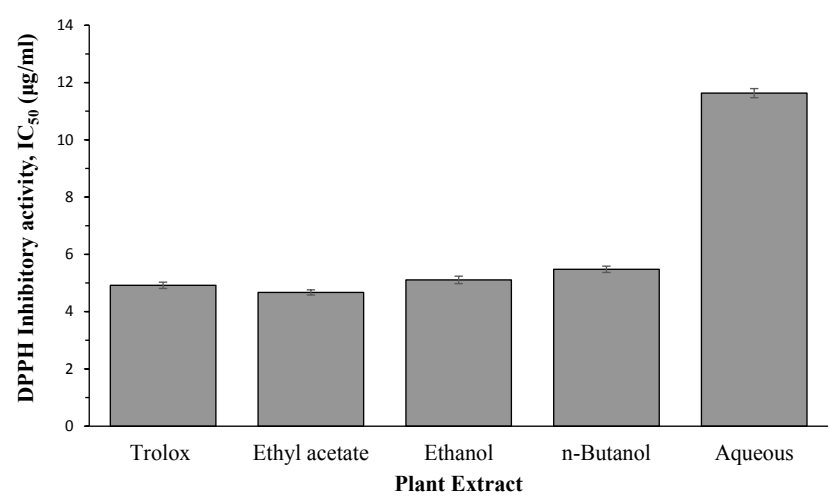

Fig. 1: $\mathrm{IC}_{50}$ of ethanol extract and three fractions of Eucalyptus citriodora kino in DPPH assay

DPPH inhibitory activities of the extract and the three fractions were expressed as $\mathrm{IC}_{50}(\mu \mathrm{g} / \mathrm{ml})$. Values are means \pm SD of three experiments.

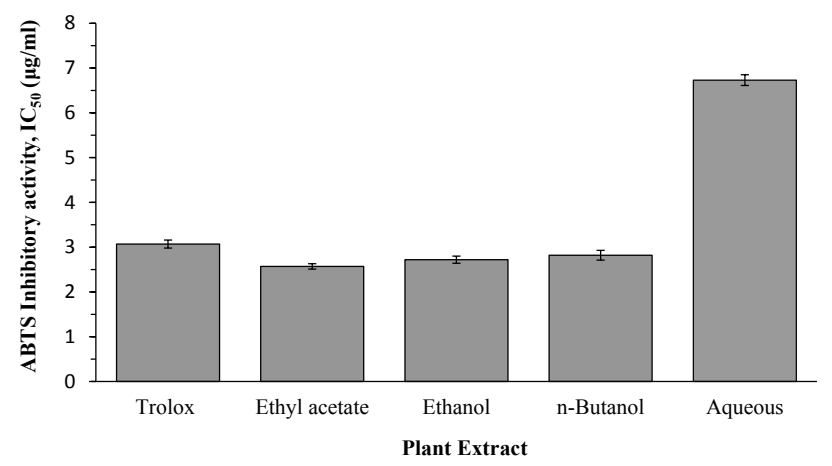

Fig. 2: $\mathrm{IC}_{50}$ of ethanol extract and three fractions of Eucalyptus citriodora kino in ABTS assay

ABTS inhibitory activities of the extract and the three fractions were expressed as $\mathrm{IC}_{50}(\mu \mathrm{g} / \mathrm{ml})$. Values are means \pm SD of three experiments

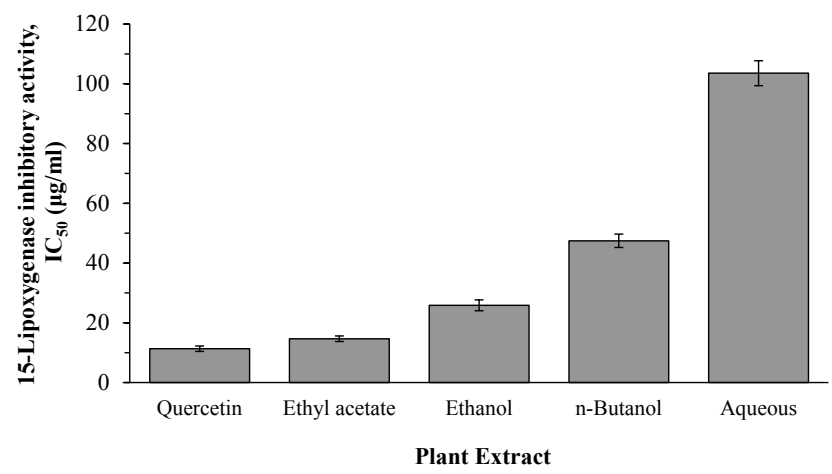

Fig. 3: $\mathrm{IC}_{50}$ of ethanol extract and three fractions of Eucalyptus citriodora kino in the 15-Lipoxygenase assay

15-Lipoxygenase inhibitory activities of the extract and the three fractions were expressed as $\mathrm{IC}_{50}(\mu \mathrm{g} / \mathrm{ml})$. Values are means \pm SD of three experiments

Results showed that all extracts were able to scavenge DPPH and ABTS free radical and inhibit 15-lipoxygenase. The EtOAc fraction showed the highest total phenolic and flavonoid content, antioxidant and lipoxygenase inhibitory activity. This finding revealed that the DPPH and ABTS free radical scavenging and lipoxygenase inhibitory activity of ethanol extract and its three fractions were highly correlated to their phenolic and flavonoid content. Polyphenols, flavonoid and other phenolic compounds, can act as electron donors and can react with DPPH and ABTS free radical and convert them to more stable products $^{[21]}$. Polyphenols can inhibit lipoxygenase by chelating the iron of the active site of the lipoxygenase and/or by reducing the ferric form of the enzyme to an inactive ferrous form ${ }^{[22-24]}$. Therefore, the results obtained in the present study clearly indicated that the E. citriodora kino could be a potential source of natural antioxidants and lipoxygenase inhibitors, which could be used to prevent free radical and lipoxygenasemediated diseases.

\section{Acknowledgements:}

The authors thank Prof. Chang-Sheng Kuoh, Department of Biology, National Cheng Kung University, for authentication of the plant material.

\section{Financial support and sponsorship:}

Nil.

\section{Conflicts of interest:}

There are no conflicts of interest.

\section{REFERENCES}

1. Rahman K. Studies on free radicals, antioxidants and cofactors. Clin Interv Aging 2007;2:219-36.

2. Mashima R, Okuyama $\mathrm{T}$. The role of lipoxygenases in pathophysiology; new insights and future perspectives. Redox Biol 2015;6:297-310.

3. Schneider I, Bucar F. Lipoxygenase inhibitors from natural plant sources. Part 2: medicinal plants with inhibitory activity on arachidonate 12-lipoxygenase, 15-lipoxygenase and leukotriene receptor antagonists. Phytother Res 2005;19:263-72.

4. Zhang YJ, Gan RY, Li S, Zhou Y, Li AN, Xu DP, et al. Antioxidant phytochemicals for the prevention and treatment of chronic diseases. Molecules 2015;20:21138-56.

5. Silva J, Abebe W, Sousa SM, Duarte VG, Machado MI, Matos FJ. Analgesic and anti-inflammatory effects of essential oils of Eucalyptus. J Ethnopharmacol 2003;89:277-83.

6. Hillis WE, Hasegawa M. The formation of polyphenols in trees I. Administration of c glucose and subsequent distribution of radioactivity. Phytochemistry 1963;2:195-9.

7. Williams CJ. Medicinal Plants in Australia, Gums, Resins, Tannin and Essential Oils. Australia: Rosenberg Publishing; 2011. p. 70.

8. von Martius S, Hammer KA, Locher C. Chemical characteristics and antimicrobial effects of some Eucalyptus kinos. J Ethnopharmacol 2012;144:293-9. 
9. Locher C, Currie L. Revisiting kinos-an Australian perspective. J Ethnopharmacol 2010;128:256-67.

10. Moreno MI, Isla MI, Sampietro AR, Vattuone MA. Comparison of the free radical-scavenging activity of propolis from several regions of Argentina. J Ethnopharmacol 2000;71:109-14.

11. Lopes FC, Bankova V, Sforcin JM. Effect of three vegetal sources of propolis on macrophages activation. Phytomedicine 2003;10:343.

12. Freitas MO, Lima MAS, Silveira ER. Polyphenol compounds of the kino of Eucalyptus citriodora. Quím Nova 2007;30:1926-9.

13. Lee SW, Hung WJ, Chen ZT. A new flavonol from the kino of Eucalyptus citriodora. Nat Prod Res 2017;31:37-42.

14. Shen KH, Chen ZT, Duh PD. Cytotoxic effect of Eucalyptus citriodora resin on human hepatoma HepG2 cells. Am J Chin Med 2012;40:399-413.

15. Duh PD, Chen ZT, Lee SW, Lin TP, Wang YT, Yen WJ, et al. Antiproliferative activity and apoptosis induction of Eucalyptus citriodora resin and its major bioactive compound in melanoma B16F10 cells. J Agric Food Chem 2012;60:7866-72.

16. Singleton VL, Orthofer R, Lamuela-Raventós RM. Analysis of total phenols and other oxidation substrates and antioxidants by means of Folin-Ciocalteu reagent. Methods Enzymol 1999;299:152-78.

17. Yen WJ, Wang BS, Chang LW, Duh PD. Antioxidant properties of roasted coffee residues. J Agric Food Chem 2005;53:2658-63.

18. Mensor LL, Menezes FS, Leitao GG, Reis AS, dos Santos TC, Coube CS, et al. Screening of Brazilian plant extracts for antioxidant activity by the use of DPPH free radical method. Phytother Res 2001;15:127-30.

19. Re R, Pellegrini N, Proteggente A, Pannala A, Yang M, RiceEvans C. Antioxidant capacity applying an improved ABTS radical cation decolourisation assay. Free Radic Biol Med 1999;26:1231-7.

20. Lyckander IM, Malterud KE. Lipophilic flavonoids from Orthosiphon spicatus as inhibitors of 15-lipoxygenase. Prostaglandins Leukot Essent Fatty Acids 1992;4:159-66.

21. Mathew S, Abraham TE, Zakaria ZA. Reactivity of phenolic compounds towards free radicals under in vitro conditions. J Food Sci Technol 2015;52:5790-98.

22. Ha TJ, Shimizu K, Ogura T, Kubo I. Inhibition mode of soybean lipoxygenase-1 by quercetin. Chem Biodivers 2010;7:1893-903.

23. Sadik CD, Sies H, Schewe T. Inhibition of 15-lipoxygenases by flavonoids: structure-activity relations and mode of action. Biochem Pharmacol 2003;65:773-81.

24. Maqsood S, Benjakul S. Comparative studies of four different phenolic compounds on in vitro antioxidative activity and the preventive effect on lipid oxidation of fish oil emulsion and fish mince. Food Chem 2010;119:123-32. 